\title{
Feeding convergence among ray-finned fishes: Teeth of the herbivorous actinopterygians from the latest Permian of East European Platform, Russia
}

Maciej Pindakiewicz, Mateusz Tałanda, Tomasz Sulej, Grzegorz Niedźwiedzki, Andrey G. Sennikov, Alexandr S. Bakaev, Valeriy V. Bulanov, Valeriy K. Golubev, and Alla V. Minikh Acta Palaeontologica Polonica 65 (1), 2020: 71-79 doi:https://doi.org/10.4202/app.00620.2019

A unique functional adaptation to herbivory within early ray-finned fishes is exemplified by the late Permian actinopterygians within the family Eurynotoidiidae with policuspid teeth strongly modified with respect to the primitive actinopterygian conditions. Here we report additional finds of multidenticulated teeth from the fluvial latest Permian deposits of Russia. The teeth belong to the members of endemic Eurynotoidiidae and show rather high morphological diversity. We confirm that the Russian forms are the earliest known ray-finned fishes with substantial modifications of teeth adapted to the processing of food. These finds confirm some previous suggestions that the adaptation to herbivory first developed in freshwater fishes, not marine. We found very similar dental adaptations in some groups of Recent freshwater teleosts, especially in characiforms and cichlids. It suggests that sympatric species of Permian Eurynotoidiidae explored various herbivorous niches like modern fish in East African lakes. Apparently, this first pulse of adaptive radiation in ray-finned fishes was probably caused by diversification of Permian aquatic vertebrate community.

Key words: Actinopterygii, Eurynotoidiidae, multicuspid teeth, herbivory, convergence, Permian, Russia.

Maciej Pindakiewicz [mpindakiewicz@twarda.pan.pl] and Tomasz Sulej [sulej@twarda.pan.pl ], Institute of Paleobiology, Polish Academy of Sciences, Twarda 51/55, 00-818 Warsaw, Poland. Mateusz Tałanda [m.talanda@biol.uw.edu.pl ] (corresponding author), Department of Palaeobiology and Evolution, Faculty of Biology, Bio logical and Chemical Research Centre, University of Warsaw, Warsaw, Poland. Grzegorz Niedźwiedzki [grzegorz.niedzwiedzki@ebc.uu.se ], Department of Organismal Biology, Evolutionary Biology Center, Uppsala University, Norbyvägen 18A, 75236 Uppsala, Sweden. Andrey G. Sennikov [sennikov@ paleo.ru ], Valeriy V. Bulanov [bulanov@paleo.ru], Valeriy K. Golubev [vg@paleo.ru ], Borissiak Paleontological Institute of the Russian Academy of Sciences, Profsoyuznaya Str. 123, Moscow 117647, Russia; and Kazan Federal University, Institute of Geology and Petroleum Technologies, 
Kremlyovskaya Str. 4, Kazan 420008, Russia. Alexandr S. Bakaev [alexandr.bakaev.1992@mail.ru ], Borissiak Paleontological Institute of the Russian Academy of Sciences,

Profsoyuznaya Str. 123, Moscow 117647, Russia. Alla V. Minikh [a.v.minih@mail.ru], Saratov State University, Astrakhanskaya Str. 83, Saratov 410012, Russia.

This is an open-access article distributed under the terms of the Creative Commons Attribution License (for details please see creativecommons.org), which permits unrestricted use, distribution, and reproduction in any medium, provided the original author and source are credited.

Forif Full text $(627.9 \mathrm{kB})$ 